\title{
Comparison of the Mechanical Characteristics of Fibers and Cell Walls from Moso Bamboo and Wood
}

Yanhui Huang ${ }^{a, *}$ and Benhua Fei ${ }^{b}$

\begin{abstract}
Bamboo and wood fibers are important raw materials for pulp and papermaking, as well as fiber-reinforced composites. The mechanical properties of single fibers and the cell walls of moso bamboo (Phyllostachys heterocycla), Masson pine (Pinus massoniana), and Chinese fir (Cunninghamia lanceolata) were tested via single fiber tensile test and nanoindentation; their fracture characteristics were also compared. The single fibers and cell walls of moso bamboo had superior mechanical properties compared with those of Masson pine and Chinese fir. The bamboo fibers exhibited high strength, high elasticity, and superior ductility. The results indicated that the differences between the mechanical properties of the fiber cells and cell walls of moso bamboo and those of wood were largely dependent upon cell shape and structure.
\end{abstract}

Keywords: Moso bamboo; Single fiber; Cell walls; Nanoindentation; Mechanical properties

Contact information: a: Key Laboratory of Wooden Material Science and Application, Ministry of Education, Beijing Forestry University, Beijing 100083 China; b: International Center for Bamboo and Rattan, Beijing 100102 China; *Corresponding author: huangyanhuizhou@163.com

\section{INTRODUCTION}

Wood fibers have always been an important raw material for pulp and papermaking, fiberboard, and fiber-reinforced composites. Seeking high performance papers, early investigators studied the mechanical properties of wood fibers (Klauditz et al. 1947; Page et al. 1972). To aid in efficiently choosing and using wood and wood fibers and to explore the formation of the tree and its cell walls, researchers have systematically studied the mechanical properties of single wood fibers (Navi et al. 1995, 2009; Groom et al. 2002; Burgert et al. 2005). Recently, wood fibers have attracted considerable attention for their imparting fiber-reinforced and nanofiberreinforced composites with desirable mechanical properties, for example, specific stiffness, and strength (Herrera-Franco and Valadez-Gonzalez 2005; Sandeep and Yan 2015). The cell wall gives the fibers and their composites their mechanical properties. Therefore, many researchers have focused on the mechanical properties of wood cell walls (Gindl et al. 2002; Wu et al. 2009; Meng et al. 2013).

Bamboo is very similar to wood in its material properties and utilization. Bamboo and wood fibers are both hollow with slender, sharp cells. Their cell walls are composed of primary and secondary walls, and the chemical constituents include cellulose, hemicellulose, and lignin, corresponding to the backbone, the matrix, and the incrusting matter, respectively. However, bamboo has a shorter growth period and usually can be harvested in less than 3 years (Zhang et al. 2002). Young (less than one year old) moso bamboo (Phyllostachys heterocycla) culm has been used to make traditional paper, which has been used for religious paper, calligraphy paper, and the reprinting of ancient books 
(Fu 2001). With the gradual reduction of wood resources, the research, development, and utilization of bamboo materials of shorter growth cycle are attracting wide interest ( $\mathrm{Yu}$ et al. 2007; Huang et al. 2012a).

Masson pine (Pinus massoniana) and Chinese fir (Cunninghamia lanceolata) are two important commercial species in southern China, and their forestations account for 40 to $62.5 \%$ and 30 to $45 \%$ of total commercial forest, respectively. They have been the main raw materials for papermaking and industrial fiber. Moso bamboo is another important raw material, especially for high grade paper ( $\mathrm{Fu} 2001)$. The mechanical properties of original materials directly affect the performances of related products. Therefore, in this study, the mechanical properties of fiber cells and cell walls from Masson pine, Chinese fir, and moso bamboo were investigated. Their differences were compared to analyze the main factors affecting the mechanical properties and to better understand the performance of paper and fiber-reinforced materials made from bamboo fibers. The results will also contribute to better scientific understanding of bamboo and wood fibers, and they will supply quantifiable indicators for making highly valued paper and fiber-reinforced composites.

\section{EXPERIMENTAL}

\section{Materials}

Masson pine and Chinese fir samples were from trees about 40 years old and collected from the mixed plantation of fir and pine at an altitude of 300 to $450 \mathrm{~m}$ from the Huangshan Gongyi Forest Farm in the Anhui province of China. After the trees were felled, a disc of $5 \mathrm{~cm}$ thickness was selected at a $1.3 \mathrm{~m}$ height; the center strip of $5 \mathrm{~cm} \times$ $1.5 \mathrm{~cm}$ (longitudinal $\times$ tangential) was cut from the pith. A slice of $1 \mathrm{~mm}$ (radial) thickness was sawn from the mature region at about the $25^{\text {th }}$ annual ring in the center strip.

Moso bamboo was collected from Miaoshanwu Forest Farm in Fuyang City, Zhejiang province, China, which is located in the north of the subtropics with an altitude of 50 to $536.9 \mathrm{~m}$. Four-year-old moso bamboo with a well-grown and straight stem was cut. A block of about $5 \mathrm{~cm} \times 1 \mathrm{~cm}$ (longitudinal $\times$ tangential) was sawn in the middle of the bamboo node near $2 \mathrm{~m}$ height, and then a slice of $1 \mathrm{~mm}$ (radial) thickness was taken from the block with the distance between the slice and the outer surface of the bamboo as $1 \mathrm{~mm}$ in radius.

First, the microfibril angles (MFA) of these slices were measured by X-ray diffraction, as detailed in Huang et al. (2012b). Next, the slices were cut into sticks with dimensions of $1 \mathrm{~mm} \times 1 \mathrm{~mm} \times 15 \mathrm{~mm}$ (radial $\times$ tangential $\times$ longitudinal). Afterward, some of the sticks were macerated in a solution of 4 parts $30 \%$ hydrogen peroxide, 5 parts glacial acetic acid, and 21 parts pure water, for the purpose of getting individual fibers. Some of the sticks were coated with gold to provide adequate conductivity and then imaged using a field emission scanning electron microscope (XL30 ESEM FEG, FEI Company, Hillsboro, OR, USA) at an accelerating voltage of $10 \mathrm{kV}$. The rest of the sticks were embedded in Spurr resin (Spurr 1969) using embedding tubes. These samples were vacuumed for $12 \mathrm{~h}$ and then vacuum-dried at $70{ }^{\circ} \mathrm{C}$ for $8 \mathrm{~h}$.

\section{Single Fiber Tensile Test}

Under a stereoscopic microscope, resin droplets of about $200 \mu \mathrm{m}$ diameter were 
placed on the two ends of the single fibers using fine tweezers. After treating all fibers on a plastic board, the fiber samples were oven-dried at $60{ }^{\circ} \mathrm{C}$ until the resin had cured fully. Samples were then conditioned at $25^{\circ} \mathrm{C}$ and $20 \%$ relative humidity before testing. A high resolution mechanical tester (MicroTester 5848, Instron, Norwood, MA, USA) integrated with a special fiber-gripping and microscopy imaging system was used to measure the single fiber properties at a strain rate of $0.8 \mu \mathrm{m} / \mathrm{s}$ and a gauge length of about $0.8 \mathrm{~mm}$, as described previously (Huang et al. 2012a). After testing, the cross-sectional areas of single fibers were measured by confocal laser scanning microscopy (LSM 510 Meta, Zeiss, Oberkochen, Germany) in order to calculate the precise mechanical properties of the fibers; the three-dimensional images of single fibers were also scanned to compare the differences between bamboo and wood (Groom et al. 2002; Huang et al. 2012a). More than 25 groups of data were obtained for specimens. The fracture characteristics of broken single fibers, sputter-coated with gold, were observed by field emission scanning electron microscopy.

\section{Nanoindentation Measurements}

The Spurr resin embedded sample was cut into a pyramid by a sharp blade. Followed by being fixed on the sample stage of ultra-microtome (Leica EM-UC7, Leica Microsystems Wetzlar GmbH, Wetzlar, Germany), the sample was cut into a smooth surface by a glass knife and then polished using a diamond knife. Before testing, the samples were balanced in the chamber of a nanoindentation instrument (TriboIndenter, Hysitron TI 950, USA) for more than $12 \mathrm{~h}$ at $22{ }^{\circ} \mathrm{C}$ and $40 \%$ relative humidity. The nanoindentation instrument was equipped with a Berkovich indenter less than $100 \mathrm{~nm}$ in diameter. The loading-unloading rate was $50 \mu \mathrm{N} / \mathrm{s}$, and the loading, load holding, and unloading times were $5 \mathrm{~s}$. More than 25 effective data points were obtained for each group.

\section{RESULTS AND DISCUSSION}

\section{Mechanical Properties of Single Fibers}

The measurement data of single fibers from bamboo and wood are summarized in Table 1. The average tensile strength and MOE (modulus of elasticity) of Masson pine and Chinese fir were very similar, about $850 \mathrm{MPa}$ and $22 \mathrm{GPa}$, respectively. The mean break strain was less than $4 \%$. Groom et al. (2002) used a similar method to test the tensile strength and MOE of loblolly pine fibers, which ranged from 410 to $1422 \mathrm{MPa}$ and 6.55 to $27.5 \mathrm{GPa}$, respectively. Burgert et al. (2002) also reported that the ultimate tensile strength and MOE of Norway spruce were $1186 \mathrm{MPa}$ and $22.6 \mathrm{GPa}$, respectively. For break strain, all samples gave the value of about $4 \%$ for mature fibers with MFA at approximately $10^{\circ}$. In this study, the mechanical properties of Masson pine and Chinese fir fibers were consistent with these results.

The mechanical properties of moso bamboo single fibers are shown in Table 1. 
Table 1. Mechanical Properties of Single Fibers from Wood and Bamboo

\begin{tabular}{|c|c|c|c|c|c|}
\hline & $\begin{array}{c}\text { Cross-sectional } \\
\text { Area }\end{array}$ & $\begin{array}{c}\text { Breaking } \\
\text { Load }\end{array}$ & $\begin{array}{c}\text { Tensile } \\
\text { Strength }\end{array}$ & MOE & $\begin{array}{c}\text { Break } \\
\text { Strain }\end{array}$ \\
\hline & $\left(\mu \mathrm{m}^{2}\right)$ & $(\mathrm{mN})$ & $(\mathrm{MPa})$ & $(\mathrm{GPa})$ & $(\%)$ \\
\hline Masson pine & $365.30(0.24)$ & $315.83(0.34)$ & $885.97(0.31)$ & $22.22(0.27)$ & $3.98(0.28)$ \\
\hline Chinese fir & $256.33(0.20)$ & $207.16(0.23)$ & $822.20(0.23)$ & $22.77(0.19)$ & $3.70(0.26)$ \\
\hline Moso bamboo & $139.27(0.22)$ & $200.60(0.24)$ & $1469.24(0.22)$ & $31.90(0.16)$ & $5.04(0.30)$ \\
\hline
\end{tabular}

Note: The data in brackets are coefficients of variation.

The mean cross-sectional area of moso bamboo single fibers was small, at 139.3 $\mu^{2}$, and the average tensile strength, MOE, and break strain were $1469 \mathrm{MPa}, 31.9 \mathrm{GPa}$, and $5.04 \%$, respectively. Furthermore, the largest breaking strain was $8.33 \%$. These values agree very well with those obtained by Wang et al. (2014) and earlier from Huang et al. (2012a).

As shown in Table 1, the mean cross-sectional area of single fibers of moso bamboo was only about one third or two thirds of those of wood, while their mean breaking load was almost two thirds that of Masson pine and nearly equal to that of Chinese fir. In addition, the mean tensile strength, MOE, and break strain were $65.8 \%$, $43.6 \%$, and $26.6 \%$ greater, respectively, than those of Masson pine and $78.7 \%, 40.1 \%$, and $36.2 \%$ greater, respectively, than those of Chinese fir. Compared with wood single fibers, despite somewhat low performance in the mean breaking load due to small crosssectional size, moso bamboo single fibers show outstanding performance in other mechanical properties, especially the mean tensile strength and MOE. Robson and Hague (1995) reported that hemp single fibers had a tensile strength of $900 \mathrm{MPa}$ and a MOE of $25 \mathrm{GPa}$. In another study, ramie fibers had an average break stress of $621 \mathrm{MPa}$, fracture strain of $1.9 \%$, and Young's modulus of $47.5 \mathrm{GPa}$ (Lodha and Netravali 2002). These results indicate that moso bamboo single fibers had high strength, high elasticity, and better ductility than many other plant fibers.

As shown in Fig. 1a, the diameter of moso bamboo single fibers was small, about $14 \mu \mathrm{m}$, and the double-wall thickness near the outer surface of bamboo was more than 10 $\mu \mathrm{m}$. Consequently, the cell lumen was so small that the whole fiber nearly as a solid structure. The cross sections of Masson pine and Chinese fir single fibers are shown in Figs. $1 \mathrm{~b}$ and 1c. The diameter of their earlywood was about $40 \mu \mathrm{m}$, and most of their double-wall thickness was less than $8 \mu \mathrm{m}$. As for latewood single fibers, the diameter and the double-wall thickness are about $30 \mu \mathrm{m}$ and $10 \mu \mathrm{m}$, respectively (Bao et al. 1998). The area of cell lumen of wood single fibers was large and accounted for more than $60 \%$ of their total area. Hence, moso bamboo single fibers could be considered as solid cylindrical structures tapered at both ends, while Masson pine and Chinese fir single fibers were internally hollow and thinly walled cylindrical structures with two subacute ends. During tensile process, the wood single fiber with the thinly walled and largely lumened structure was susceptible to buckling and breakage (Eder et al. 2009). Buckling under tension was primarily observed in thin-walled fibers. Thick-walled fibers resisted buckling because the critical buckling stress depends on the response of the fiber to bending stresses in the cell wall (Page and El-Hosseiny 1983; Eder et al. 2009). Therefore, cell geometry played a major role affecting the mechanical properties of single fibers. 

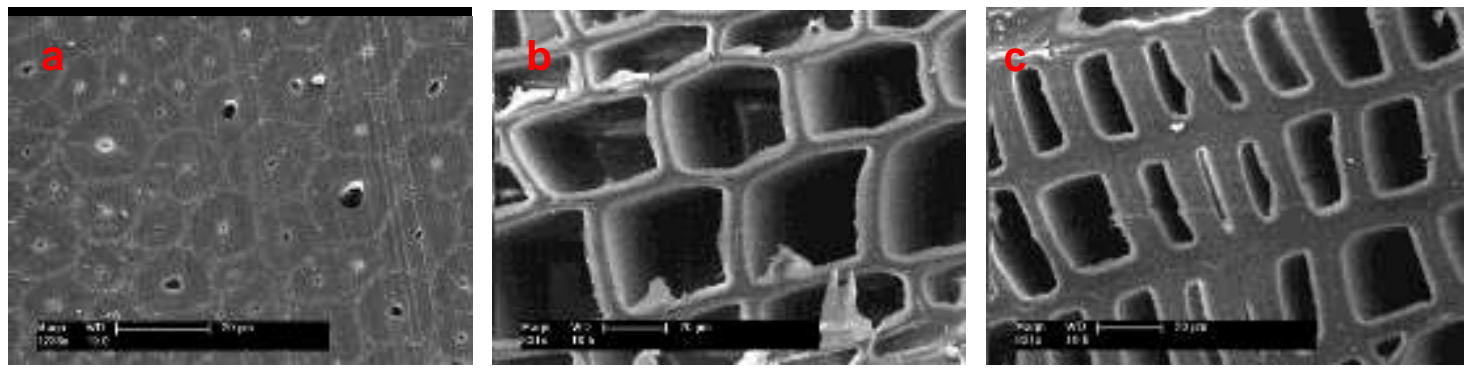

Fig. 1. Cross sections of moso bamboo (a), Masson pine (b), and Chinese fir (c) fibers Note: All the scale bars are $20 \mu \mathrm{m}$.

Moso bamboo, Masson pine, and Chinese fir fibers are biological materials with pits to transport water and nutrients on their cell walls. Pits amount to natural defects on the cell wall because fiber fractures caused by stress concentration often occur at or around pit locations when the fiber is subjected to tensile stress. Bordered pits and sideby-side double pits greatly exacerbate the incidence of fracture. Thus, a large variation of MFA near pits and severe stress concentration cause fractures (Mott et al. 1996; Shaler et al. 1997). Eder et al. (2009) confirmed that pits have an important effect on the fracture and mechanical properties of single fibers. As shown in Fig. 2a, there were very few, simple pits of small size on the cell wall of moso bamboo fiber. In Masson pine and Chinese fir fibers in Fig. $2 \mathrm{~b}$ and $2 \mathrm{c}$, the pits on the cell wall were bordered pits of large sizes and quantities, usually in a single-row or two-row pattern, and distributed in both earlywood and latewood fibers. Therefore, the break strains of Masson pine and Chinese fir fibers were lower than that of moso bamboo fibers.
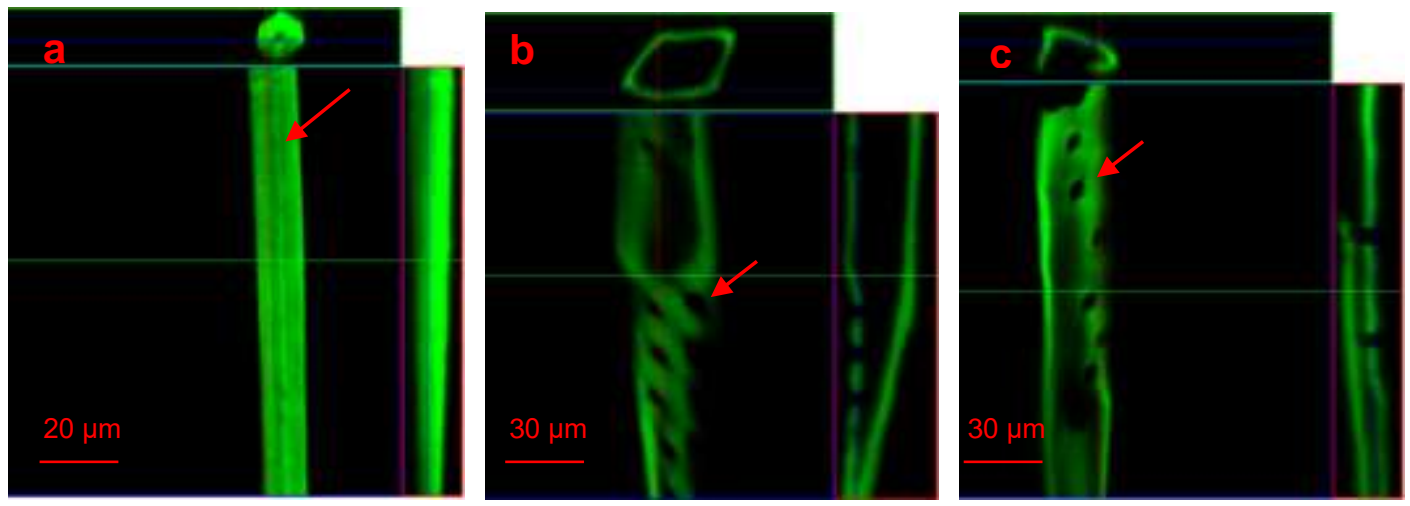

Fig. 2. Pits of moso bamboo (a), Masson pine (b), and Chinese fir (c), as imaged by confocal laser microscope 


\section{Mechanical Properties of Secondary Cell Walls}

Results for hardness and MOE are shown in Fig. 3.

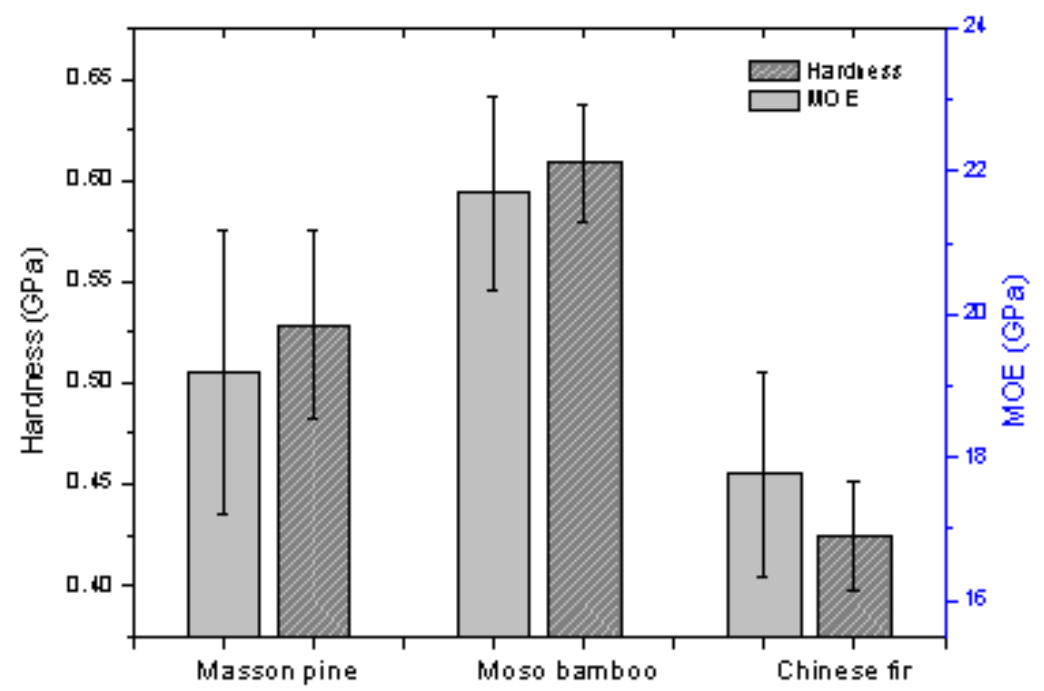

Fig. 3. Mechanical properties of secondary cell walls from Masson pine, moso bamboo, and Chinese fir fibers

The differences of nanoindentation modulus (NI modulus) and nanoindentation hardness (NI hardness) of secondary cell walls were small for both the earlywood and latewood fibers of mature Masson pine and Chinese fir in the preliminary experiment. Therefore, in this study, the test data of NI modulus and hardness from earlywood and latewood were calculated together, with detailed results shown in Fig. 3. The NI modulus and hardness of secondary cell walls of Masson pine were $19.18 \mathrm{GPa}$ and $0.53 \mathrm{GPa}$, respectively, while those of moso bamboo (21.69 $\mathrm{GPa}$ and $0.61 \mathrm{GPa}$ ) were $19.9 \%$ and $23.6 \%$ higher than those of Masson pine and $22.1 \%$ and $43.5 \%$ higher than those of Chinese fir (17.8 GPa and $0.42 \mathrm{GPa}$ ). These results are similar to those obtained by Wu $e t$ al. (2009) and Wang et al. (2014).

From the standpoint of composite materials mechanics, fibers are treated as microfiber-reinforced composite materials embedded in a matrix of hemicelluloses and lignin. The angle between microfiber direction and principal axis direction, the microfibril angle (MFA), has been negatively correlated with the NI modulus of fiber secondary walls (Page et al. 1983; Yu et al. 2007). The average MFA of Masson pine was $12.6^{\circ}$, while that of Chinese fir was $15.6^{\circ}$, both larger than that of moso bamboo, which was $9.8^{\circ}$. The moso bamboo secondary cell wall was multilayered, with alternating nanoscale thin layers and microscale thick layers. The lumens were very small, and the fibers had very small and few pits. This stable structure provided strong support and less variability of NI values for the probe of the nanoindentation apparatus. Therefore, the small MFA and distinct cell wall structure of moso bamboo resulted in its superior mechanical properties.

The difference between Masson pine and Chinese fir in hardness and MOE was attributable to the difference of the average MFA and density. The MFA of Masson pine was $12.6^{\circ}$, lower than that of Chinese fir, which led to a large MOE value for Masson pine due to the negative correlation of MFA and MOE (Page et al. 1983; Yu et al. 2007); for density, the value of Masson pine was also larger than that of Chinese fir; therefore, the hardness of the pine was also big (Gindl et al. 2002; Wu et al. 2009). 
Comparing the mechanical properties of other natural fiber materials, the secondary cell walls of flax stalk fibers had an NI modulus and hardness of $17.4 \mathrm{GPa}$ and $0.39 \mathrm{GPa}$, respectively (Keryvin et al. 2015). The corresponding values for hemp and cotton stalk were $12.3 \mathrm{GPa}$ and $0.41 \mathrm{GPa}$ and $16.3 \mathrm{GPa}$ and $0.85 \mathrm{GPa}$, respectively (Li et al. 2013). Almost all of these values are lower than those of moso bamboo. In summary, the cell walls of mature bamboo fibers have superior mechanical properties, indicating bamboo's potential for making high-grade paper and high-quality fiberreinforced composites.

\section{Fracture Characteristics of Single Fibers}

As observed by field emission scanning electron microscope, the typical fractures of Masson pine and Chinese fir single fibers were transverse, neat, and uniform, and they frequently occurred at pits or areas of increased stress concentration (Fig. $4 \mathrm{~b}$ and 4c). Pit fields are the most influential defects in determining the position of failure in wood fibers (Sedighi Gilani 2006). As Figs. 4b and 4c show, more pits are present near fractures (red ovals). During the tensile process, most fractures of Masson pine and Chinese fir first appeared at or near pits, after which many cellulose macromolecular chains snapped, followed by orderly transverse rupture.
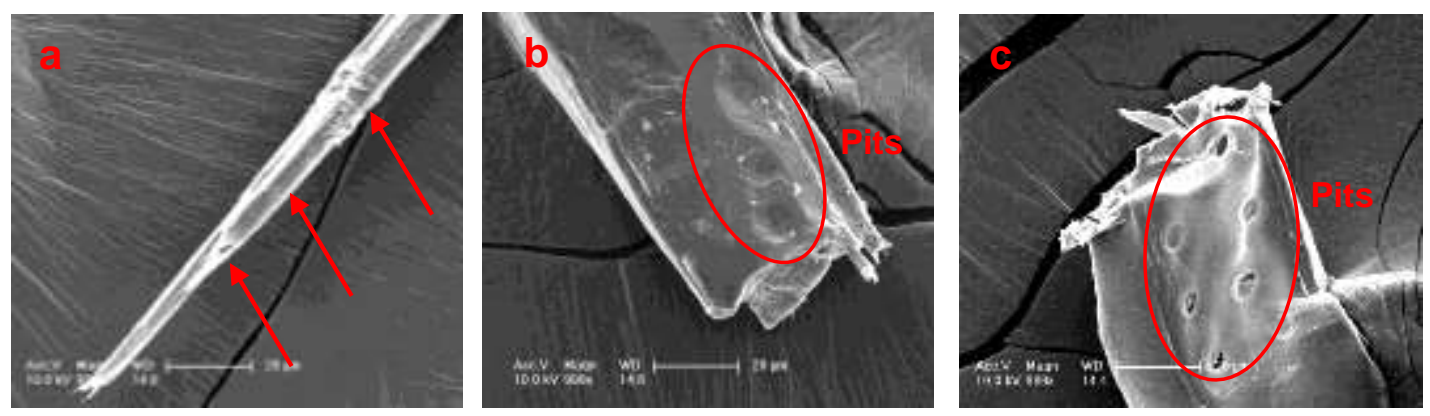

Fig. 4. Transverse fractures of moso bamboo (a), Masson pine (b), and Chinese fir (c) fibers Note: All the scale bars are $20 \mu \mathrm{m}$.

Figure 4a shows that most of the fractures of moso bamboo happened in the weak interfaces between thin and thick layers, and the fracture characteristics were predominantly those of multilevel delaminating fracture. Because of the few, simple pits of moso bamboo, this type of fracture resulted from the weak linkage between layers due to differences in MFA and layer thickness. This "brush type" fracture was also observed by Chen et al. (2017).

The cell walls of Masson pine and Chinese fir fibers consist of a primary and a secondary wall, and the secondary wall composes more than $70 \%$ with only three layers. Bamboo cell walls have more than ten layers, with different MFA in each layer, and alternate repeatedly between nanoscale thin layers and microscale thick layers (Liese 1998). In addition, the thickness ratio of cell wall to lumen for moso bamboo is about 15 , indicating a very small lumen, while those for Masson pine and Chinese fir are about 0.5. Due to the alternating narrow and wide layers, a smaller mean MFA, a greater thickness ratio of wall to lumen, and limited, simple pits, the mechanical properties and ductility of moso bamboo fibers were best, and they were resistant to fracture. 


\section{CONCLUSIONS}

1. The mean tensile strength, MOE, and break strain of moso bamboo single fibers were more than 65\%, 40\%, and 26\% greater than those of Masson pine and Chinese fir single fibers, respectively.

2. The mean NI modulus of secondary cell walls of moso bamboo fibers was $21.7 \mathrm{GPa}$, and their NI hardness was $0.61 \mathrm{GPa}$. These parameters of moso bamboo were, respectively, $19.9 \%$ and $23.6 \%$ greater than those of Masson pine and $22.1 \%$ and $43.5 \%$ greater than those of Chinese fir.

3. Transverse fracture was the main fracture mode for the Masson pine and Chinese fir single fibers. However, multilevel delaminating fracture was dominating for the moso bamboo single fibers.

4. It was determined that the mechanical properties of moso bamboo fibers and cell walls were superior, with the moso bamboo fibers having high strength, high elasticity, and greater ductility. The differences of mechanical properties among them were largely correlated to their cell shape and structure.

\section{ACKNOWLEDGMENTS}

This project was funded by the National Natural Science Foundation of China (31500472 and 31370563).

\section{REFERENCES CITED}

Bao, F., Jiang, Z., and Fei, B. (1998). Wood Properties of Main Tree Species from Plantation in China, China Forestry Publishing House, Beijing, China.

Burgert, I., Eder, M., Frühmann, K., Keckes, J., Fratzl, P., and Stanzl-Tschegg, S. (2005). "Properties of chemically and mechanically isolated fibres of spruce (Picea abies [L.] Karst.). Part 3: Mechanical characterisation," Holzforschung 59(3), 354-357. DOI: 10.1515/HF.2005.058.

Burgert, I., Keckes, J., Frühmann, K., Fratzl, P., and Tschegg, S. E. (2002). “A comparison of two techniques for wood fibre isolation - Evaluation by tensile tests on single fibres with different microfibril angle," Plant Biology 4(1), 9-12. DOI: $10.1055 / \mathrm{s}-2002-20430$.

Chen, H., Yu, Y., Zhong, T., Wu, Y., Li, Y., Wu, Z., and Fei, B. (2017). "Effect of alkali treatment on microstructure and mechanical properties of individual bamboo fibers," Cellulose 24(1), 333-347. DOI: 10.1007/s10570-016-1116-6.

Eder, M., Jungnikl, K., and Burgert, I. (2009). "A close-up view of wood structure and properties across a growth ring of Norway spruce (Picea abies [L] Karst.)," Trees 23, 79-84. DOI: $10.1007 / \mathrm{s} 00468-008-0256-1$.

$\mathrm{Fu}$, J. (2001). "Chinese moso bamboo: Its importance," Bamboo 22(5), 5-7.

Gindl, W., Gupta, H. S., and Grünwald, C. (2002). "Lignification of spruce tracheid secondary cell walls related to longitudinal hardness and modulus of elasticity using nano-indentation," Canadian Journal of Botany 80(10), 1029-1033. DOI: 
10.1139/B02-091.

Groom, L. H., Mott, L., and Shaler, S. M. (2002). "Mechanical properties of individual southern pine fibers. Part I. Determination and variability of stress-strain curves with respect to tree height and juvenility," Wood and Fiber Science 34(1), 14-27.

Herrera-Franco, P. J., and Valadez-González, A. (2005). "A study of the mechanical properties of short natural-fiber reinforced composites," Composites B 36(8), 597608. DOI: 10.1016/j.compositesb.2005.04.001.

Huang, Y., Fei, B., Yu, Y., and Zhao, R. (2012a). "Plant age effect on mechanical properties of moso bamboo (Phyllostachys heterocycla var. pubescens) single fibers," Wood and Fiber Science 44(2), 196-201.

Huang, Y., Fei, B., Yu, Y., and Zhao, R. (2012b). "Modulus of elasticity and hardness of compression and opposite wood cell walls of Masson pine," BioResources 7(3), 3028-3037.

Keryvin, V., Lan, M., Bourmaud, A., Parenteau, T., Charleux, L., and Baley, C. (2015). "Analysis of flax fibres viscoelastic behaviour at micro and nano scales," Composites A 68, 219-225. DOI: 10.1016/j.compositesa.2014.10.006.

Klauditz, W., Marschall, A., and Ginzel, W. (1947). "Zur Technologie verholzter pflanzlicher Zellwände," Holzforschung 1(4), 98-103.

DOI: 10.1515/hfsg.1947.1.4.98.

Li, X., Wang, S., Du, G., Wu, Z., and Meng, Y. (2013). "Variation in physical and mechanical properties of hemp stalk fibers along height of stem," Industrial Crops and Products 42, 344-348. DOI: 10.1016/j.indcrop.2012.05.043.

Liese, W. (1998). "The anatomy of bamboo culms," International Centre for Bamboo and Rattan (Technical report), 7-99. ( https://books.google.ca/books?hl=zh-CN\&lr= \&id=dIVAGsXNPSsC\&oi=fnd\&pg=PA3\&ots=vBiJQIdGt4\&sig=IWo9ymu_rXh_UeFopPkdAMZ6Fk\&redir_esc=y\#v=onepage \&q\&f=false)

Lodha, P., and Netravali, A. N. (2002). "Characterization of interfacial and mechanical properties of "green" composites with soy protein isolate and ramie fiber," Journal of Materials Science 37, 3657-3665. DOI: 10.1023/A:1016557124372.

Meng, Y., Wang, S., Cai, Z., Young, T. M., Du, G., and Li, Y. (2013). “A novel sample preparation method to avoid influence of embedding medium during nanoindentation," Applied Physics A 110(2), 361-369. DOI: 10.1007/s00339-012-7123-z.

Mott, L., Shaler, S. M., and Groom, L. H. (1996). "A technique to measure strain distributions in single wood pulp fibers," Wood and Fiber Science 28(4), 429-437.

Navi, P., Rastogi, P., Gresse, V., and Tolou, A. (1995). "Micromechanics of wood subjected to axial tension," Wood Science and Technology 29(6), 411-429. DOI: $10.1007 / \mathrm{BF} 00194199$.

Navi, P., and Stanzl-Tschegg, S. (2009). "Micromechanics of creep and relaxation of wood. A review," Holzforschung 63(2), 186-195. DOI: 10.1515/HF.2009.013.

Page, D. H., and El-Hosseiny, F. (1983). "The mechanical properties of single wood pulp fibres. Part VI: Fibril angle and the shape of the stress-strain curve," Journal of Pulp and Paper Science 9, 99-100.

Page, D. H., El-Hosseiny, F., Winkler, K., and Bain, R. (1972). "The mechanical properties of single wood-pulp fibres. Part I: A new approach," Pulp and Paper Magazine of Canada 73(8), 72-77.

Robson, D., and Hague, J. (1995). in: Proceedings of the conference on wood fiberplastic composites, Forest Products Society: Madison, Wisconsin, USA.

Sandeep, S. N., and Yan, N. (2015). "Effect of high residual lignin on the thermal 
stability of nanofibrils and its enhanced mechanical performance in aqueous environments," Cellulose 22, 3137-3150. DOI: 10.1007/s10570-015-0737-5.

Sedighi Gilani, M. (2006). A Micromechanical Approach to the Behaviour of Single Wood Fibers and Wood Fracture at Cellular Level, Ph.D. Dissertation, University of Tehran, Iran. DOI: 10.5075/epfl-thesis-3546.

Shaler, S. M., Egan, A., Mott, L., and Landis, E. N. (1997). "Fracture and micromechanics of resinated fibers," in: The Fourth International Conference on Woodfiber-Plastic Composites, pp. 32-39.

Spurr, A. R. (1969). "A low-viscosity epoxy resin embedding medium for electron microscopy," Journal of Ultrastructure Research 26, 31-43. DOI: 10.1016/S00225320(69)90033-1.

Wang, H., An, X., Li, W., Wang, H., and Yu, Y. (2014). "Variation of mechanical properties of single bamboo fibers (Dendrocalamus latiflorus Munro) with respect to age and location in culms," Holzforschung 68(3), 291-297. DOI: 10.1515/hf-20130081.

Wu, Y., Wang, S. Q., Zhou, D. G., Xing, C., and Zhang, Y. (2009). "Use of nanoindentation and SilviScan to determine the mechanical properties of 10 hardwood species," Wood and Fiber Science 41(1), 64-73.

Yu, Y., Fei, B. H., Zhang, B., and Yu, X. (2007). "Cell-wall mechanical properties of bamboo investigated by in situ imaging nanoindentation," Wood and Fiber Science 39(4), 527-535.

Zhang, Q. S., Guan, M. J., and Ji, W. L. (2002). "Variation of Moso bamboo chemical compositions during mature growing period," J. Nanjing For. Univ. 26(2), 7-10.

Article submitted: June 6, 2017; Peer review completed: September 3, 2017; Revised version received and accepted: September 16, 2017; Published: September 19, 2017. DOI: 10.15376/biores. 12.4.8230-8239 